\title{
THE GOD OF SMOKE: TESTIMONIES
}

\author{
Michelle Esquivias \\ University of the Philippines, Diliman \\ ellie.esquivias@gmail.com
}

\begin{abstract}
About the Author
Michelle Esquivias is currently a senior taking up English Studies (Language) in University of the Philippines, Diliman. Her poems have appeared in The Literary Apprentice, Cha, and transit. Her first chapbook, An Introduction to Vases, was published last year.
\end{abstract}




\begin{abstract}
A building is burning. A name takes flight into the expanse, stumbling as it tries to become itself. Against the resistance of the sky. Basic stowaway education. Learning the way of combing the clouds into a home. A star dies out. Those below call out unknowingly, to what is there dampening the horizon-no longer the rain. Overture of departure, the name is bellowed: fire, fire There is a hesitant quiver in their cries.
\end{abstract}




\section{The God of Smoke}

Testimonies 


\section{Birthday}

bowl of wonton noodle hitting

fissure, backroom dirty kitchen.

slit-eye peep at a thurible chain

snapping.

the smack of globe against marble.

a sudden congregation of

hisses at the street corner

tricycle hub.

Yet sometimes with barely a stir I start past piled leaves petals paper garbage. Billowing into birth, en route past unwanted, the immediate past, as if without knowing, as if without. 


\section{From a growing list of what you call sins}

A rolled up piece of paper dwindling to a crisp, when something dies, when something heaves, a tall block of painted cement fraying at the corner. A series of inhalations, trees preventing forest fires, but not always. Hikers' baited breath, vaporous name from their mouths, "civil twilight," the campsite unheeded, until (see pyrolysis, separation by fire: actually, see tribulation). Housewives doing all the work: combustions by the hour. A burning ship going down in water: a lit cigarette floating along city innards: factory workers mining in the dark-two out of three things reported on the news. But pre-meditated glowing! negligible soundbite of a match hitting the pavement!: a hundred ravages wasted. 


\section{Letter from an outsider}

We do not dare call it what it is. Instead, tendril. Instead, arm. Reaching out to cradle us in the bustle of the afternoon. Instead, haze. We only wade through its embrace because we love what we cannot escape. Instead, shape. Forming in between us. Instead, kin. Instead, the thing we like to take pictures of. 